\title{
SCHIZOPHRENIA AND PSYCHOMOTOR ACTIVITY
}

\section{Caldas ${ }^{1}$, C. Pereira ${ }^{1}$, I. Pinto ${ }^{1}$, J. Peta ${ }^{1}$, S. Nascimento ${ }^{1}$. \\ ${ }^{1}$ Medical trainee at Centro Hospitalar Psiquiátrico de Lisboa, Lisbon, Portugal}

\section{Introduction}

As stated by Bleuler, more than $50 \%$ of people diagnosed with schizophrenia (SCZ) present persistent or recurrent catatonic symptoms (Walther). It is now possible to understand that alterations in motor activity, such as dyskinesia and psychomotor slowing, have been frequently described in SCZ.

\section{Objective}

Understand the association between Schizophrenia and psychomotor activity disorders.

\section{Method}

The authors conducted a literature review by searching the Pubmed database using the keywords Schizophrenia; psychomotor activity; Catatonia; risk factors.

\section{Results}

There is an association between medicated patients and non-medicated patients, as it is possible to interpret from the knowledge that $66 \%$ of nevermedicated patients, during their first episode, reported at least one motor symptom, against $80 \%$ of chronically medicated patients. In addition, an association has been found between significant reduction in movement speed and other reduced psychomotor activity symptoms, such as catatonia,parkinsonism, and even with negative symptoms of SC.

\section{Conclusion}

The appearance of motor symptoms in SCZ patients is linked to the development of the human motor system. The most frequent catatonic symptoms associated to SCZ are stereotypies, mannerisms and mutism, but also impairment of volition. It is also relevant to pay close attention to the difficulty in differentiating the slowing of the psychomotor activity associated with negative symptoms from drug-induced parkinsonian bradykinesia.

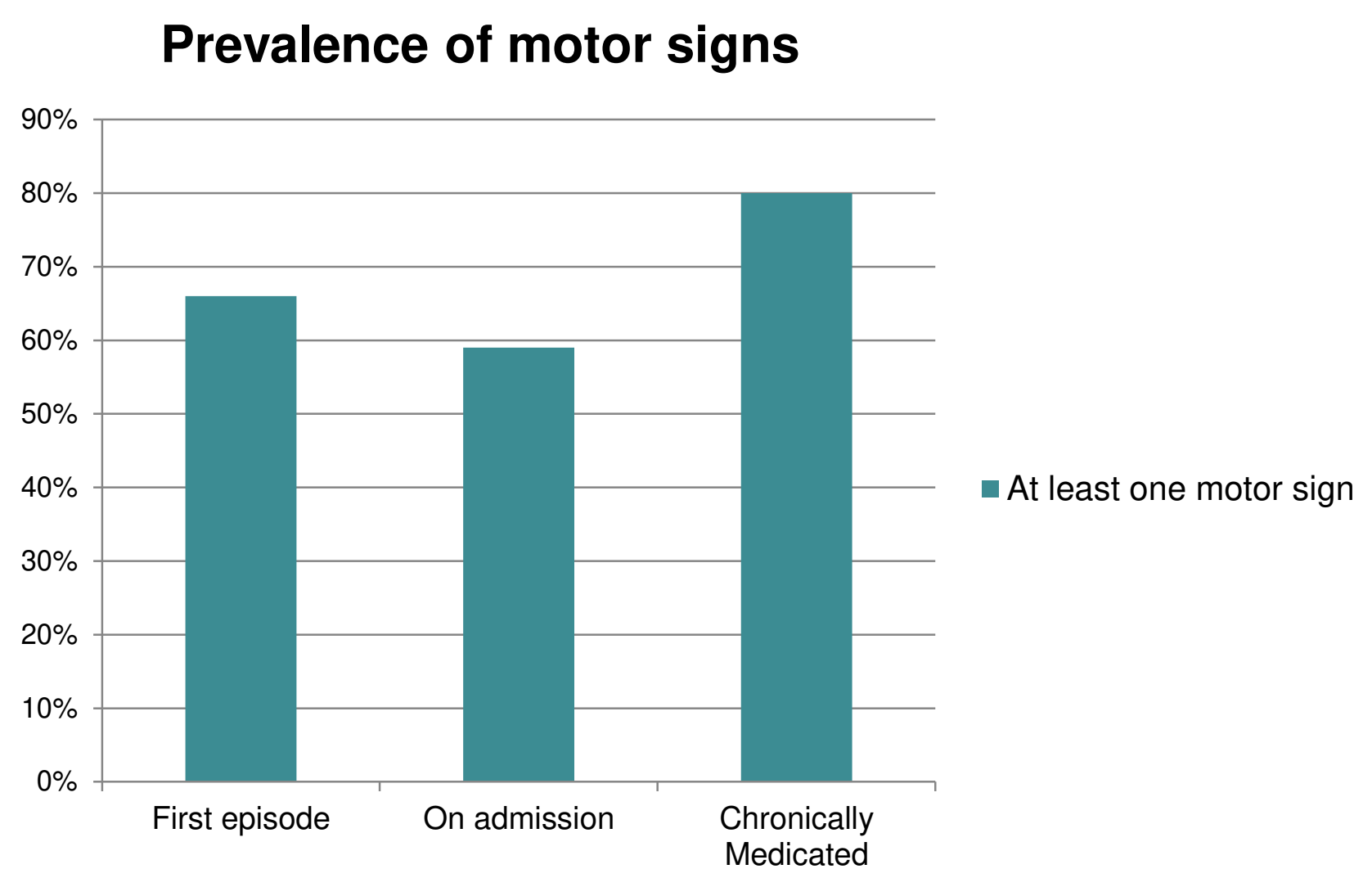

Michael P. Caligiuri, Hans-Leo Teulings, Charles E. Dean, James B. Lohr, The Nature of Bradykinesia in Schizophrenia Treated with Antipsychotics, Psychiatry Research (2019), doi: https://doi.org/10.1016/j.psychres.2019.01.058

Haralanov, S., Haralanova, E., Milushev, E., Diana Shkodrova, D.,Claussen, CF. Objective and quantitative equilibriometric evaluation of individual locomotor behaviour in schizophrenia: Translational and clinical implications. J Eval Clin Pract. 2018;1-11. DOI: 10.1111/jep.12917 Lisia,G., Nicob, D., Ribolsia, M., Niolua, C.,Lacquanitic, F., Siracusanoa, A., Dapratic, E. Asymmetries in initiation of aiming movements in schizophrenia. Neuropsychologia 109 (2018) 200-207.

Walther, S., Strik, W. Motor Symptoms and Schizophrenia. Neuropsychobiology 2012;66:77-92. DOI: 10.1159/000339456 